\section{METEOROLOGY OF BEN NEVIS}

THE cairn on the top of Ben Nevis marks, as is well known, the highest spot in the British Islands, and when the question of high-level meteorological observations came to be seriously entertained some years ago attention was drawn to this position as the best afforded in these islands for a first-class meteorological observatory which would form one of the more important members in the network of the high-level stations of the Continent. The advantages of the situation are enhanced by the consideration that the mountain rises directly from the level of the sea to a height of 4406 feet, and that its summit stands from 2000 to 3000 feet clear above the mountain ridge to westward which lies between it and the Atlantic. The mountain thus raises its head in the very midst of the west-south-westerly winds from the Atlantic, which exercise so preponderating an influence on the meteorology of Europe. Among the results from observations made at this elevated situation the more important to be looked for are those which relate to the greater movements of the atmosphere, particularly the upper currents in their relations to the cyclones and anti-cyclones of Europe, the data for the investigation of some of the laws regulating these movements being obtained by a comparison on the one hand of observations made on Ben Nevis with those made at the other high-level stations of Europe, and on the other with those made at lower levels, and published in the different Daily Weather Reports.

When therefore the Scottish Meteorological Society (last spring) accepted the handsome offer of Mr. Clement L. Wragge to ascend Ben Nevis every morning in time to make observations on the top at 9 a.m., every care and precaution was taken as regards the quality of the instruments procured, and in the arrangements made for their exposure and protection, so as to make the observations first-class, as far as this could be secured without constant residence on the top or the erection of continuously recording instruments. Further, as it is contemplated to build an observatory on the top, the arrangements regarding the instruments and their positions were carried out, so that all that will be required to complete the observatory is simply the erection of a suitable residence for the observers.

That Mr. Wragge possessed not only enthusiasm, but also strength of will, skill, and readiness of resource, was soon manifested. He met the Council of the Society in Edinburgh on May 26 and 27, was in Fort William on the following day, and on Tuesday, the 3 rst, fixed and secured the instruments in proper position on the top of the Ben, including a massively-built cairn for the reception of the barometer. On June I, at 9 a.m., the observations were regularly begun, and have since been continued without the break of a single day up to the disastrous storm of October I4. This continuity, so extremely desirable in such a series of observations, was guaranteed by Mr. Wragge securing at the outset the services of a well-qualified assistant, whom he trained to the work, as well as a second assistant, whom he also trained, to meet any emergency that might arise.

The instruments are these :-A barometer inclosed in a cairn, $6 \frac{1}{2}$ feet high and 17 feet in circumference, which incloses a strong box fastened with lock and key, with a second door protecting the box from heavy rains and the gusts of wind which blow up the narrow gullies of the tremen dous precipices, I 800 feet high, only a few paces off, and sweep over the instruments with terrific fury. A Stevenson's screen, with maximum, minimum, dry and wetbulb thermometers, the bulbs of which are 4 feet above the mountain stone; the box opens to north, and also contains the ozone tests. The other instruments are a terrestrial minimum radiation thermometer, a solar maximum radiation thermometer, 4 feet high, and a raingauge, 8 inches in diameter, and its rim I foot high. Fig. I shows Stevenson's thermometer screen in elevation, erected on four stout posts, having angle-sloping stanchions, by which the box was securely and immovably fixed.

This arrangement continued till the end of July, when, as the tourist season was then setting in, a more effectual protection of the thermometers was necessary, so as to prevent the possible occurrence of any crowding of tourists immediately around the thermometers, or any other interference which might vitiate the readings made daily at so heavy an expenditure of time and trouble. In order to afford the required protection, Mr. Stevenson designed a strong wire cage, measuring five feet each way, the wirenetting being supported by strong iron rods continued downwards beyond the cage, and bent below at right angles. The horizontal projecting rods below are weighted with heavy blocks of stone, so as to secure complete stability to the structure. In the interior of the cage the Stevenson screen, with the thermometers and ozone tests, is placed, and firmly secured with supports.

Fig. 2 is a sketch of the station, kindly prepared by $\mathrm{Mr}$. Wragge, which will explain, better than any verbal description could do, the arrangements which have been carried out with regard to the instruments, and also the remarkable character of the plateau at the top of Ben Nevis. A is the barometer cairn; $\mathrm{B}$, the wire cage, with the thermometer screen seen inside ; $C$, the solar maximum radiation thermometer, a black-bulb in vacuo, the terrestrial radiation thermometer being placed on one of the stones adjacent; $\mathrm{D}$, the rain-gauge; and $\mathrm{E}$, the but, covered

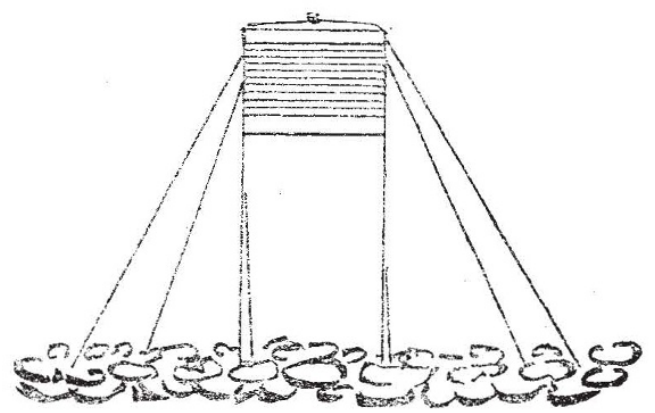
FIG. I.-Stevenson's thermoneter scresn as fixed on Ben Nevis shown in
elevation.

with tarpaulin and built of the surrounding stones for shelter to the observer. The cairn of the Ordnance Survey is distant twenty-five paces north-westwards from the barometer cairn.

Under instructions from the Council of the Scottish Meteorological Society I inspected the station on the top of the Ben on July 28 , and on the following day the station at Fort William, where observations are carefully and intelligently made by Mrs. Wragge as nearly as possible at the same instant of time that observations are made at the top and at the different points on the outward and homeward journeys. We left Fort William about halfpast five on Thursday morning, the party consisting of Mr. Wragge, Dr. Sanderson, the Society's honorary treasurer, Mr. R. C. Sanderson, and myself, as well as Mr. Wragge's Newfoundland dog, Renzo, that daily accompanies him in his ascents. The instruments are read at Fort William before starting, and the first observation on the journey is made at a peat bog, which was reached at 6.12 a.m., Mr. Wragge dismounting and reading his aneroid and sling thermometer, and noting the wind, clouds, and other observations of the weather. The lake was reached at 7.23 a.m., where the third set of observations were made, including the temperature of the water of the lake, which was $48^{\circ} 3$, being $3^{\circ} \circ$ higher than that of the air. Here our ponies were left, and Mr. Wragge pushed on, in order to reach the top in time for the regular 9 a.m. observation, while we followed more at leisure. 


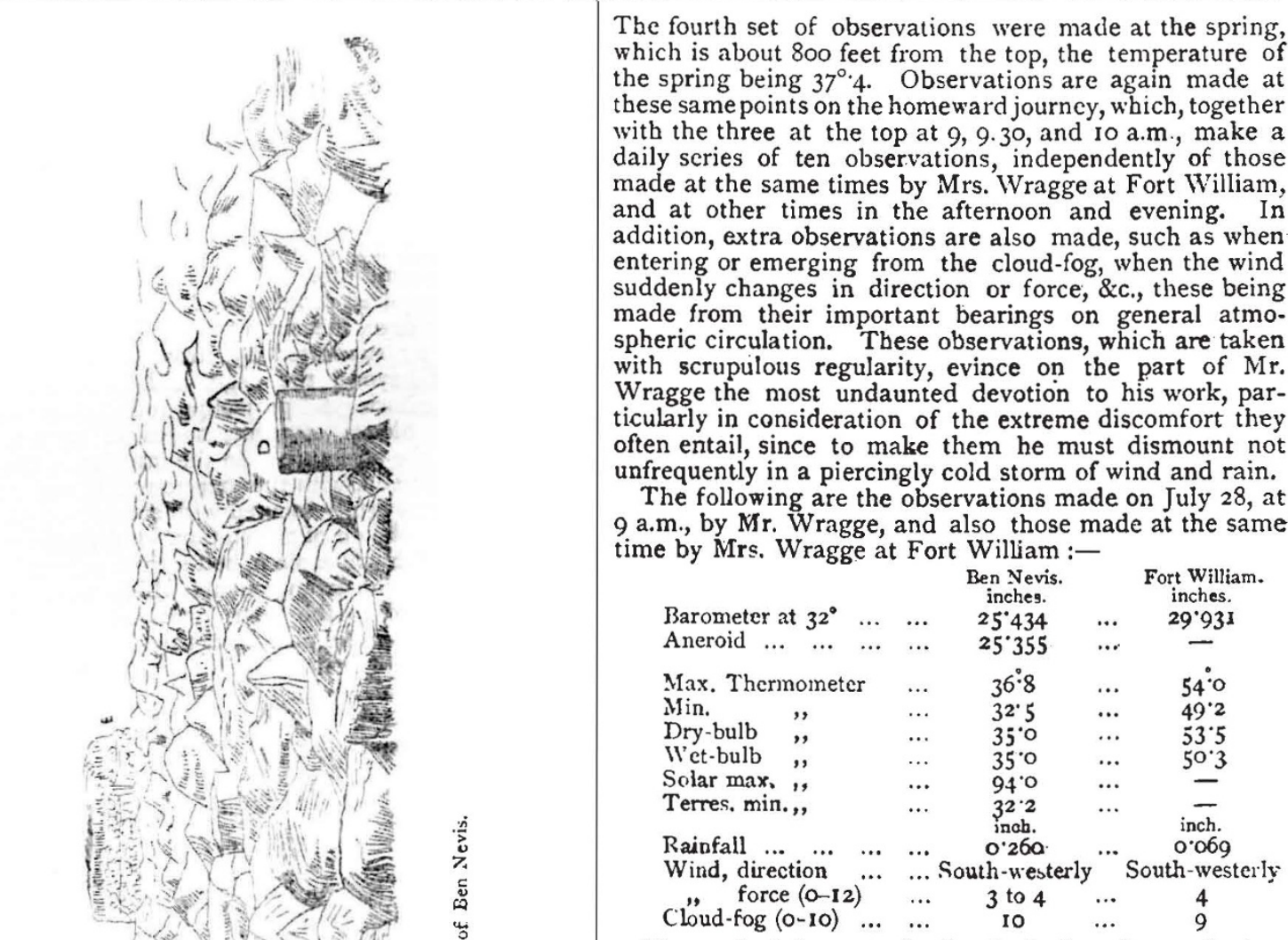

We reached the summit shortly before eleven, the last 1000 feet of the ascent having been through a dense cloudfog, which clung persistently to the mountain the whole time we were on it. We found the protecting wire cage in its position, having been placed there on the previous day, but the Stevenson screen was still in the position it bad occupied since the observations began, and as is shown in Fig. I. A reading of the instruments having been made, the workmen proceeded to remove the thermometer-box to its new position inside the wire cage, as represented in Fig. 2, and the party withdrew to the hut, whicb, though containing only one apartment, 8 feet by 4 feet, and its walls far from wind-tight, afforded a most. welcome sheiter from the bitterly cold masses of mingled fog, Scotch mist, and sleety drizzle which drifted across the mountain. A fire was quickly lighted in the middle of the hut with splinters of wood and balls of tow steeped in paraffin, the excessive dampness of everything rendering the use of paraffin indispensable. The inspection which followed showed that the full equipment of instruments wcre in excellent order and in excellent positions, and that the observations were made with a precision and a fidelity which left nothing to be desired.

At the time of our visit everything was drenched with wet. On opening the thermometer-box the whole inside presented the appearance of having been just lifted out of water, a drop hanging from the bulbs of the dry and other thermomcters. Mr. Wragge informed us that during the fifty-one days preceding our visit the drybulb thermometer was found on opening the box to be without the drop hanging from it only on six occasions.

A noteworthy feature of the meteorology of Ben Nevis is the winds. Repeated instances were seen, during the ascent and descent, of a thin filmy fragment of mist suddenly appearing over one of the glens, which on being watched was observed slowly to ascend, lengthening and becoming denser as it rose, frequently assuming. in time an appearance resembling the smoke rising from a burning mountain. $\mathrm{Cn}$ one occasion the whole of that 
part of Glen Nevis seen from our position was clear of cloud and mist, but in a brief space of time, not exceeding five seconds, a dense mist suddenly filled the whole breadth of the glen, the upper limit of the cloud-fog being only a little lower than the level of our position. These facts point to ascensional movements in the atmosphere over Ben Nevis, which in all probability are caused by the temperature of the surface of the mountain being higher than that of the enveloping atmosphere at the same heights. These ascensional movements are disturbing influences on the winds prevailing on the Ben, but especially at the top, the result being that it is frequently difficult, if not impossible, to say what the true direction of the wind is, as it is found to blow from all points of the compass within the space of a few minutes.

In the accompanying sketch (Fig. 2) Mr. Wragge has given a faithful representation of the surface of the plateau of the summit. This plateau consists of about ninety acres, the difference of level between any two points of which does not exceed ten feet. It is throughout strewn to a depth of about four feet, with blocks of felstone lavas and volcanic agglomerates, nearly all tilted up to such a degree that the only mode of progression is over the sharp edges of the stones. These blocks are different from the rock of the mountain itself, the nearest rock resembling them

\section{THE ELECTRIC TRAMWAV}

$\mathrm{NE}$ of the most interesting sights in counection with the Exhibition at Paris is the electrical tramway; it is a practical evidence of the great future in store for being found in Glencoe, twelve miles distant. No soil is anywhere visible, the heavy rains doubtless having long ago washed it all down hill ; indeed, except in small detached patches, the mountain is wholly bare of soil for the last I 500 feet of the ascent.

That the striking bareness of Ben Nevis is due to the excessive rains having washed away the soil, and not to the climate, is shown by the remarkably well-grown specimens of Cerastium alpinum, C. trigynium, Saxifraga stellaris, and Alchemilla alpina, which were found at heights closely approaching 4000 feet in situations which protected the soil from being carried away by the rains. In a small patch only 240 feet from the summit, I. gathered a. small grown specimen of Saxifraga stellaris in flower, and in the same patch there was growing a Carex, which however showed no flower. Excepting the above flowers and Sagina saxatilis, Carex rigida, Luzula spicata, and a single specimen of Sibbaldia procumbens, I did not notice any other flowering plants which a botanist would take. the trouble to put into his vasculum. The scanty flora of Ben. Nevis as regards the rarer species is thus in striking contrast to the rich floras of Ben Lawers and many others of our Scottish mountains, a circumstance which may perhaps possess some geological significance.

\section{ALEXANDER BUCHAN}

electricity as a motive power. From an article in $\mathrm{La}$ Nature we give some of the leading features of this recent application of electricity. In the case of a tramway the question is a complicated one, for the rails cannot be isolated, and they therefore cannot be used as

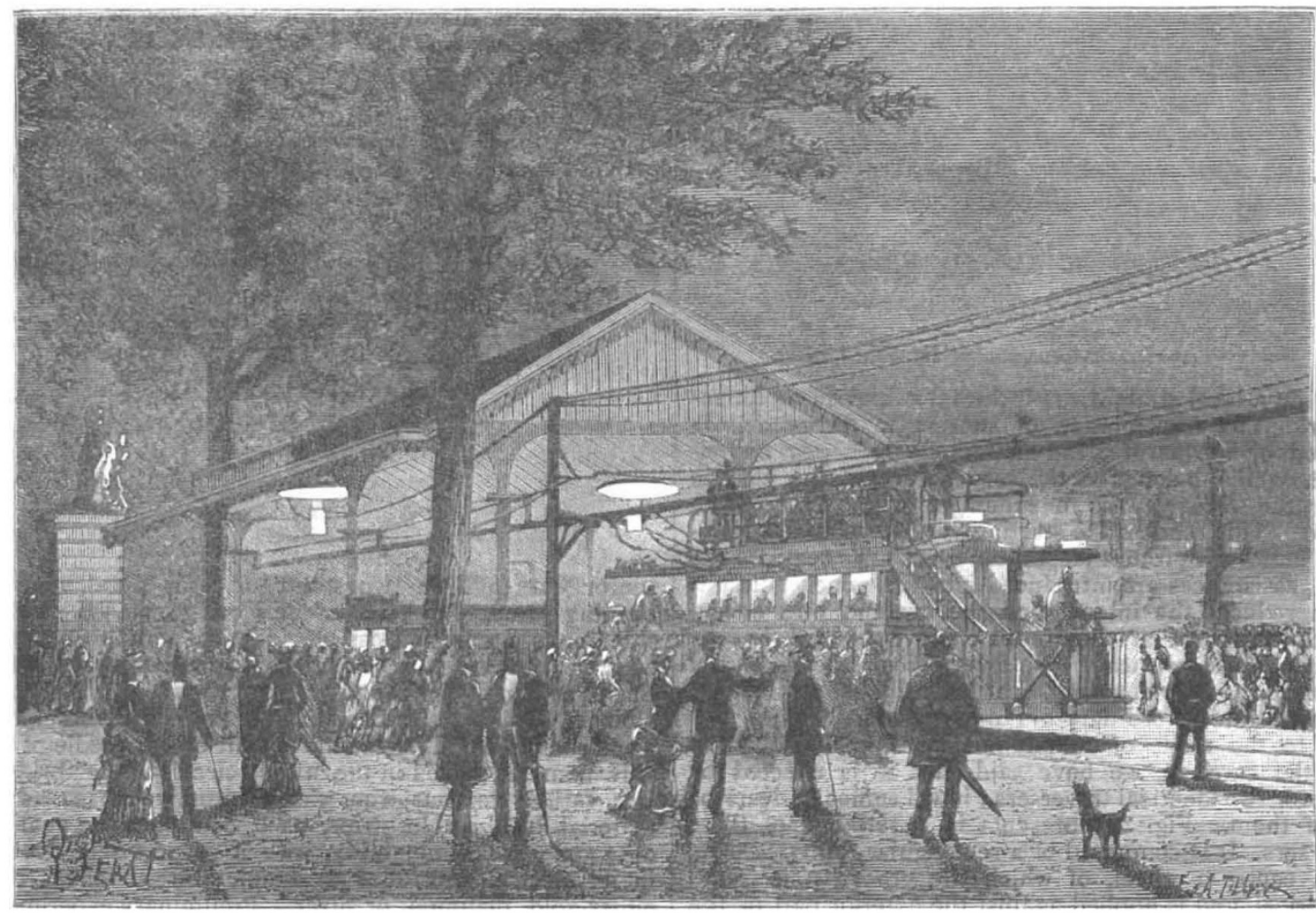

FIG. x.-Siemens' Electric Tramway; Departure Station at the Place de la Concorde.

conductors. How then, in these conditions, is the motor of the carriage connected with the fixed generator placed in the Exhibition at the Palais de 1 Industrie? This is the problem which MM. Boistel and Sappey, the engineers of Miessrs. Siemens, have completely solved, after several fruitless attempts, which almost always precede successes of this kind. In the preliminary experiments made at the workshop in the Rue Picot, they made use, as conductors, of a brass tube electrically connected with the carriage by a traverser, the function of which we 